iodide, are handy measures for preliminary examinations of urine at the bedside of the patient for determining the presence of albumin in the urine.

Fourth:-That to be entirely reliable, the correcting influence of heat must be employed in applying all these newer tests.

Fifth:-That the potassio mercuric iodide, and sodium tungstate tests, and also the test papers of Dr. Oliver, are undoubtedly valuable acquisitions to our resources; inasmuch that through their greater delicacy and more ready applicability, they are likely to lead more frequently to resort to the microscope, and thus detect the early stages of certain forms of nephritis, which might otherwise escape observation, till too late to save or prolong life.

Sixth:-That the question of the near future, as to albumin in urine is likely to be, not only is it present, but what quantity of albumin in the urine constitutes a fathological condition? and this question must be largely determined by the microscope.

68 Madison St.

\section{EXPECTANT TREATMENT IN SOME CASES OF ABORTION.}

BY ADDISON H. FOSTER, M.D.

Mrs. A., American, aged 30 , multipara, was taken, Christmas day, 1877 , with severe labor pains, and expelled a four months' foetus with very little hæmorrhage.

She being very fleshy, the firmly contracted os could barely be reached, and no active interference for the delivery of the placenta was advised. After a rest in bed for a week the patient was allowed to resume her usual household duties. Every few days a little hæmorrhage occurred, with some pain, and about once a month a portion of the placenta was expelled, until the 3 oth of April, or after four months, the last piece, the size of the thumb, came away as fresh and healthy as any before it. There never occurred any serious hæmorrhage or severe pains during the four months, and very little medicine was taken. The patient often went to town on the street-cars, a ride of over two and one-half miles; was in bed but a few days in all, and never had any symptoms of inflammation, and repeated digital examinations always disclosed a firmly-con tracted os, with no tenderness. She helped to move May I, and made an excellent recovery without any untoward result.

August 15, I880, she again aborted at the fourth month, the placenta remaining under circumstances similar to the first. Upon getting up, after a week, considerable hæmorrhage and local tenderness occurred. A tampon of carbolized cotton arrested the hæmorrhage and allayed all the tenderness, so that the patient was up and about immediately, until October 18 , when the secundines came away entire with very little hæmorrhage, and no local tenderness or troubles followed.
In March, $x 88 \mathrm{r}$, she again aborted at about three months, and the placenta was discharged entire in two weeks, with no serious hæmorrhage. She was doing well until one cold evening two days after, contrary to orders, she got up and went to the theater, bringing on considerable metro-cellulitis, which was aggravated almost constantly by the obstinacy of the patient in refusing to remain quiet. I believe she would have had no complications if she had rested in bed for two weeks.

This case illustrates others in my experience, where, with a firmly contracted os and no material hæmorrhage, especially in a fleshy patient, with the uterus beyond easy reach without introducing the hand into the vagina, the organ is left to the efforts of nature, with satisfactory results.

Repeatedly I have seen the placenta expelled a few days after the use of the carbolized tampon, with very little hæmorrhage, pain, or subsequent trouble, when the pain and tenderness had been considerable before the tampon was used.

Hence I am advocating the "vis conservatrix naturæ " in occasional cases of abortion, rather than constant violent manual interference in every case, of whatever nature.

\section{SUGGESTIONS ON THE EXAMINATION OF THE EYES} OF APPLICANTS FOR PENSION.

BY J. L. THOMPSON, M.D., PROFESSOR OF EYE AND EAR DISEASES IN THE MEDICAL COLlEGE OF

INDIANA.

(Read before the Mitchell District Medical Society, Dec. 28, 1883.)

In the examination of the eyes of applicants for pension, a more thorough knowledge of the anatomy, physiology and pathology of the organ is needed than in one's ordinary private practice, for the following reasons, to-wit:

Ist. Many of them are impostors, who really have nothing abnormal about their eyes, they, in many instances having been induced by pension agents to add eye disease to their many other real or supposed infirmities.

2d. Others have slight disease, or abnormal condition, which they greatly magnify.

3 d. In others, disease may have at one time existed and now have disappeared; but once having been on the pension rolls, they dislike to have their names stricken therefrom.

4th. Many present themselves whose troubles originated prior to their enlistment, or subsequent to their discharge from the service.

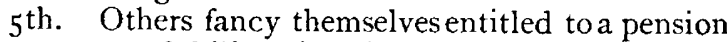
on account of failing sight incident to age, and other factors which we know have nothing to do with exposure incident to army service.

6th. On the other hand, many have been stricken from the rolls, or rated too low, or never pensioned at all, because the medical examiner has either failed to detect existing disease, or underestimated its gravity. 
Examiners should always be provided with testtypes of Snellen or others, remembering, though, that the applicant in many instances will not admit that he can read as well as he is able to, but tact and good judgment on the part of the examiner, aided by convex and concave glasses, will rarely ever fail in aiding him to reach a just conclusion in any case.

One should always have at least the following number of lenses: Convex, $1 / 42,1 / 15,1 / 10,1 \%$. Concave, $1 / 30,1 / 20,1 / 10,1 / 5,1 / 3$, for the purpose of determining whether there is an anomaly of refraction. I have skipped over many numbers, as we simply wish to determine whether an anomaly exists, and not its exact degree. Then, one needs a convex lens of two or two and a half inches focal range for the examination by oblique illumination-a means of incalculable importance when we wish to detect disease in the cornea, anterior chamber, iris, crystalline lens, anterior and posterior capsule. To use this aid, one simply needs to have a lamp placed on a level with the patient's eye and obliquely in front and to the side of the same. By this means a pencil of rays may be so thrown upon the eye as to reveal that which cannot possibly be determined by one's unaided senses. It must be practiced on healthy structure first, and practice will soon teach us at just what angle to place the light, which, if too far in front or too much to the side, will not answer the purpose.

'Then, one should be provided with one or two prisms set in a large frame, say two of $5^{\circ}$ each; one with its base placed directly upward, and the other base downward. These are preferable to colored glasses combined with prisms, in cases where the applicant complains of blindness or defective vision in one eye. Prisms placed as above necessarily cause diplopia, (double vision), and with tact one can very quickly detect which is the defective eye, by simply having the person examined to close his eyes until a given signal, when, after placing these upon him, we hold a large white sheet of paper before him with a round, black spot, cross or other mark in its center, about one foot from his face. We tell him to open his eyes and quickly tell us just where they (the spots) stand, whether the lower spot is to the right or to the left of the upper, and which one is the plainer, etc., etc. If one meets with an old practiced hand at deception, he will commence winking and blinking and shutting first one eye and then the other, but we must then quickly raise the glasses and withdraw the paper from him or he will quickly detect the scheme. All that is necessary is to practice this on oneself to thoroughly understand the action of prisms, when many other methods of using them will be suggested.

Always have a mydriatic as well as a myotic at hand, so as to be able to dilate or contract the pupil, if needed. And if you wish to know all about any given case, provide yourselves with an ophthalmoscope also, as every disease behind the lens is a sealed book, objectively, without its aid. But, fortunately, a great majority of the cases which come up for pension are those where the anterior portions of the eye are diseased.

Were these examinations usually made by the younger members of the profession, no excuse should be offered as to one's inability to use this instrument. But it is a fact that nearly all of the medical examiners are gentlemen of at least twenty years' standing in the profession, whose hours are so occupied as to prevent the long continued practice with the instrument necessary to its proper use, for it is a well known fact to experts that it requires as much daily practice with it as is necessary to the acquisition of a foreign living language. I have met with cases where physicians have brought patients to me, just simply for a confirmation of diagnosis and prognosis, where they have used the ophthalmoscope and found no disease of the fundus of the eye ; and yet I have silently, in their presence, made drawings of the gravest possible lesions. Not that I claim any superior skill in its use, but simply mention it to show that one must practice long with it before he dare pronounce positively in cases where it has been brought to one's aid.

We will now suppose that an applicant presents himself for examination. Look at his eyes thoroughly before touching them, as the slightest eversion of the lower lid will often cause such a congestion of the conjunctiva as to throw one off his guard in diagnosis. This one thorough glance takes in the surroundings of the eye, lachrymal derivative apparatus, eyelids, their movements, tarsal margins, etc., etc. We notice whether any of the cilix are inverted, or whether there is slight eversion of the lower punctum lachrymalis, remembering that if it does not hug the eye-ball closely, stillicidium, with its accompanying thickened lids and reddened conjunctiva, is always present. We notice the movements of the eye-ball, and if inverted or everted; we determine whether this is from strabismus or paralysis. Then the white of the eye, the cornea, the iris, and the lens, beyond which we cannot go without the ophthalmoscope.

We will now notice some of the affections which are very liable to be overlooked or underrated. One of them is

Cicatrization of the Superior Palpebral Conjunctiva.-Persons troubled in this way tell us that though their eyes feel very well when they present themselves before us, yet when they are called upon in harvest or threshing time, or to work in the hay-mow, or in burning brush, or in high winds, or any similar irritating employment, their eyes become very sore, and they are often disabled for weeks. In such cases the eye looks perfectly normal until we evert the upper lids, when, instead of the beautiful, smooth conjunctiva with the pearl-like meibomian glands seen beneath it, we find said conjunctiva cicatrized and hard, bound closely to the tarsal cartilage, which it very much resembles. In such cases we may rest assured that long ago the applicant had a long continued granular conjunctivitis, and that as these neoplastic growths were absorbed they destroyed the conjunctiva from which they sprang. All such persons should be pensioned, and no person so affected should ever be admitted to the army, no matter how well he sees, nor how well his eyes look, nor how much he protests that his eyes are just as perfect as any one's.

Nebulous Opacity of the Cornea. - This is an affection frequently overlooked, and many a poor fellow has had his claim rejected or his pension cut off, while 
stoutly protesting that his vision was very poor. The reason of this is, that the unaided eye cannot readily detect these cases; but no sooner does one resort to oblique illumination than the case is immediately apparent, and it is astonishing how very much the thinest, faintest possible opacity of this kind will reduce the acuity of vision.

Large, Dense Opacity of the Comea.-Where the cornea is white throughout its whole extent, or where it has entirely sloughed away in one or both eyes, be sure to thoroughly investigate the case as to the origin being in a gonorrhcea. 'Tis true, the case may come on from other causes, but do not forget this one fact deduced from extensive experience. 'The following case is interesting: $\mathrm{X}$. Y. called on me several years ago, with a copious discharge streaming from his eyes. He told me that he was recently under a doctor's care, and that said doctor had used a foul brush in his eyes, and in that way had poisoned them. I asked him if he had the clap, which he vigorously denied. He went to another physician, but came back to me in just one week with both cornex sloughed off. He threatened suit against the doctor alleged to have used the foul brush (an irregular, advertising doctor). So, to fully convince myself, I compelled him to allow me to examine his genitals. I then found a copious stream of pus from the urethra, on stroking the organ. His attorneys called upon me after they had commenced suit, and, after hearing what I had to say, dismissed the case. Three or four years afterwards this man applied for pension, for total loss of his eyes, the result of disease contracted in the army. Fortunately, the Board of $\mathbf{E x}$ aminers sent him to me for an examination, when I gave them my former experience with the case. How this matter is to be settled, so that due justice may be done to all parties, I would very much like to know. That he contracted some form of disease while in the army he can prove, and that he was under treatment for the same when he contracted the gonorrhøa which destroyed his eyes, is also well known. But the solution of this knotty point I will leave for this society and the medical referees at Washington to determine.

Diseases of the Iris.-If one is not especially on the lookout for it, no troub!e is more liable to escape one's notice than synechia posterior (adhesion of the iris to the capsule of the lens); it may be partial or total, with or without a false membrane in the pupil. Where a false membrane exists, it is liable to be mistaken for cataract. Whenever adhesions exist the eye is in great danger from occasional recurring iritis, which goes on until either the pupil is closed with or without said false membrane, or a total synechia posterior prevents the interchange between the anterior and posterior aqueous chamber, when the eye is ultimately lost from the glaucomatots process being set up, or from an irido-choroiditis. Sometimes these cases follow ulcerative keratitis, from malarious and other causes, sometimes from rheumatism; but remember that all iritic diseases should be thoroughly investigated, owing to the fact that great numbers are of syphilitic origin, especially where one notices no corneal complication nor evidence of rheumatism.
Choroidal and Ketinal Diseases._-These can only be determined positively by the aid of the ophthalmoscope. Many have been rejected when no. disease could be seen, and yet had the ophthalmoscope been used atrophied patches or pigmentary deposits might have been seen just as plainly as one sees the fruit in a freshly cut plum-pudding. Here, with this instrument can one detect between retinitis pigmentosa of congenital origin and that which is acquired later in life, as is seen in these two typical cases (shown to the society). The one was taken from a lady, at. 30 years, and you see the deposits are like minjature blackbird's feet, and are very peripherally situated, only a few approaching near to the maculalutea. The other was taken from a gentleman, about 48 years of age, where it followed an exhausting diarrhœa, in one of our Southern prisons during the late war. Here you see the patches are larger, more irregular and more centrally situated; both of them were sight-blind, as are all cases of this disease.

DISEASES AND ANOMALIES WHICH ANTEDATE ENIISTMENT.

Progressive Myopia. - Applicants often tell us that they had very good vision when they entered the service, but that during their army life their eyes became diseased, and that since leaving the service their vision has gradually or rapidly become worse. We find that they can not see test types at all, but if the man is honest he may admit that he sees some of the letters on the wall when a powerful concave lens is placed in front of the eye. Or he may want a pension more than a thorough examination, and may not admit that he sees better with any glass. In such cases one can not examine without the ophthalmoscope; but with it one may measure the degree of the myopia to within a half an inch, and can find a crescent on one side of the optic disc extending from the same, corresponding to a posterior staphyloma (bulging backwards of the back part of the eye) and often besides this large white patches where the choroid is atrophied and the sclerotic is to be seen behind.

Nystagmus (Oscillation of the Fye Balls).-Whenever this distase or symptom of disease is met with you may depend upon it that it occurred before the second year of infancy, except in the rarest cases possible, such as in paralysis agitaus, in confirmed drunkards, and in some brain or spinal affections. A typical case is as follows: A medical examining board sent a case to me where one eye was very much turned outward from divergent strabismus, he had nystagmus, and a very high degree of progressive myopia with its accompanying staphyloma porticum and white patches in the fundus, from sclerotico-choroiditis posterior. His vision was very poor. The board reported the facts to Washington, stating that the disease was not contracted in the army, but the case was returned to the board with instructions for a further examination, owing to the fact that the man had furnished evidence that he had shot at a mark and done. many things which called for a tolerably fair degree of vision, and it was asked of said board if it were not 
possible, in the light of this evidence, that they had done the man an injustice? It was not possible, it was a very well-marked case of an everyday occurrence in a large ophthalmic practice: triple evidence of its early origin was plainly manifest, nystagmus, divergent strabismus and progressive myopia. What more conclusive evidence could one wish for?

Suppose he could shoot at a mark. I have known men to shoot remarkably well, even though vision only equalled $20 \%_{100}$ with both eyes. His may have been even better than this in one eye while in the army, but I question very much its equalling $5 / 100$ in the one that had such a high degree of divergence. This brings us to

Strabismus and Paralysis.-Strabismus is usually the result of an anomaly of refraction. In the convergent form the eye is hypermetropic (rays of light are brought to a focus behind the retina), while in the divergent the eye is generally myopic (the opposite to the above). Strabismus usually comes on before the fifth year of childhood, and wherever it settles on one eye the person has binocular vision (as a prism will show) and he becomes amblyopic from exclusion (weak from disuse). 'T'is true an opacity of the cornea or other blemish sometimes causes it, but that can easily be detected as can the date of its occurrence. Paralysis, on the other band, is caused by wounds, brain disease, rheumatism and above all syphilis. Always investigate paralysis of the ocular muscles thoroughly, and never confound it with strabismus.

\section{DISEASES AND ANOMALIES JNCIDENT TO AGE.}

Senile Cataract. - This, as its name indicates, occurs in those who have passed the meridian of life. It comes on slowly; dimmer and dimmer becomes the sight, until blindness is the result. No inflammation; no pain; nothing but a failure of the nutrition of the lens, with gradual and steadily increasing opacity of the same. It is usually entirely independent of any disease contracted while in the service. Cataract may be caused by blow, or punctured wound, or from a choroidal inflammation, but it usually follows very quickly upon them; while the senile variety we meet with is in those now past fifty, who left the army with very good vision, or they may have had some conjunctival trouble for which they were treated while in the service, and as their eyes may have troubled them occasionally since their discharge, they attribute the gradually failing sight to their former trouble, for which probably they may have been drawing a pension. It is in just such cases where the line of demarkation should be strictly drawn. The government is justly indebted to such for the disability caused by the superficial trouble, but in no way for the blindness caused from cataract, as it is in no way incident to army life. Cataract is very easily detected with the plain mirror of the ophthalmoscope, or by oblique illumination. If the anterior or peripheral parts of the lens are first affected, the latter is sufficient; if only the posterior pole, the ophthalmoscope must be used.

Presbyopia in Hypermetropes.-Presbyopia is also an anomaly which creeps upon us just as certainly as does age, but if we are emmetropic (in optical measure) it only annoys us for close objects; distant ones are seen almost as distinctly as ever, but let one be hypermetropic (a condition where rays are formed behind the retina) and he is very much troubled for distant objects as well as close ones. Now, suppose one so affected (and they are numerous), had some slight eye trouble while in the service, he immediately supposes that his present falling sight is due to the former trouble, and that he should be pensioned for the same. To detect these cases, convex glasses are required, and the strongest glass, with which one sees the best across a room, or at infinite distance, indicates the degree of the manifest hypermetropia. It has no connection with army service.

Many other affections might be mentioned, but these are the main ones upon which you will be called to pass judgment.

\section{Resume :}

Cicatrization of the superior palpebral conjunctiva, even though the eye looks perfectly normal, is a just cause for pension.

A slight nebulous opacity of the cornea is easily overlooked, except by oblique illumination.

Iritic adhesions are easily overlooked, except by the use of a very delicate and oblique illumination. They are seeds of ultimate destruction unless loosened. Look for syphilis when no other cause is apparent.

Progressive myopia has its origin in childhood, but may not seriously affect vision until much later in life. It is usually accompanied by staphyloma posticum and sclerotico-choroiditis-post.

Nystagmus (oscillation of the eyeballs) is usually accompanied by defective vision, and usually has its origin in early childhood.

Strabismus is generally an affection of early childhood, and when confined to one eye, it soon very much impairs the visual acuity, and the subject has not binocular vision.

In total destruction of the cornea and in leucoma (large white opacity) investigate thoroughly for gonorrhoea.

Where the eye is turned from paralysis, and no evidence of wound of head, or eye, or of brain or spinal cord is seen, look for syphilis.

Senile cataract usually comes on long after the applicant has left the service, and though he may have evidence of granular lids or chronic conjunctivitis, and may be already on the pension rolls, still, in ninety-nine cases out of a hundred, the cataract is entirely independent of army life.

Presbyopia, wheh occurring in hypermetropes, affects vision for distant as well as close objects, and often leads the applicant to believe it to be incident to army life.

All lesions behind the lens are a sealed book, objectively, unless one resorts to the ophthalmoscope.

Allow me to say, in conclusion, that in eye diseases, a mistake in diagnosis is almost impossible, when one knows what to look for, and yet it is a fact beyond contradiction, that greater ones are made than in any other part of the human economy. 